\title{
Erratum to: Stability-Indicating HPLC and RP-TLC Determination of Cefpirome Sulfate with Kinetic Study
}

\author{
Mohamed R. Elghobashy $\cdot$ Lories I. Bebawy
}

Samah S. Abbas $\cdot$ Rafeek F. Shokry

Published online: 28 January 2014

(C) Springer-Verlag Berlin Heidelberg 2014

Erratum to: Chromatographia (2013) 76:1141-1151

DOI 10.1007/s10337-013-2516-5

Unfortunately, during the production of this article a mistake occurred in the order of the chromatograms in Fig. 1.

The correct version of Fig. 1 is given here:

The online version of the original article can be found under doi:10.1007/s10337-013-2516-5.

M. R. Elghobashy $(\bowtie) \cdot$ S. S. Abbas

Analytical Chemistry Department, Faculty of Pharmacy,

Cairo University, Kasr El-Aini St., 11562 Cairo, Egypt

e-mail: mohamedrefaat73@yahoo.com

L. I. Bebawy · R. F. Shokry

National Organization for Drug Control and Research

(NODCAR), 51 Wezaret El-Zeraa St., Dokki, Cairo, Egypt 


\section{Detector response}

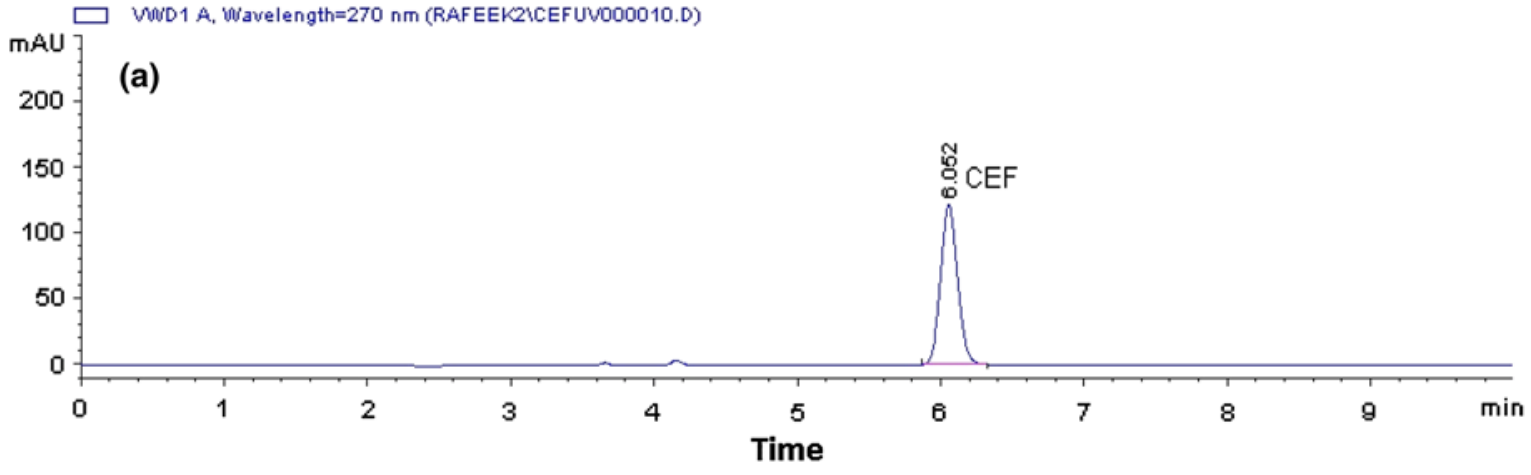

\section{Detector response}

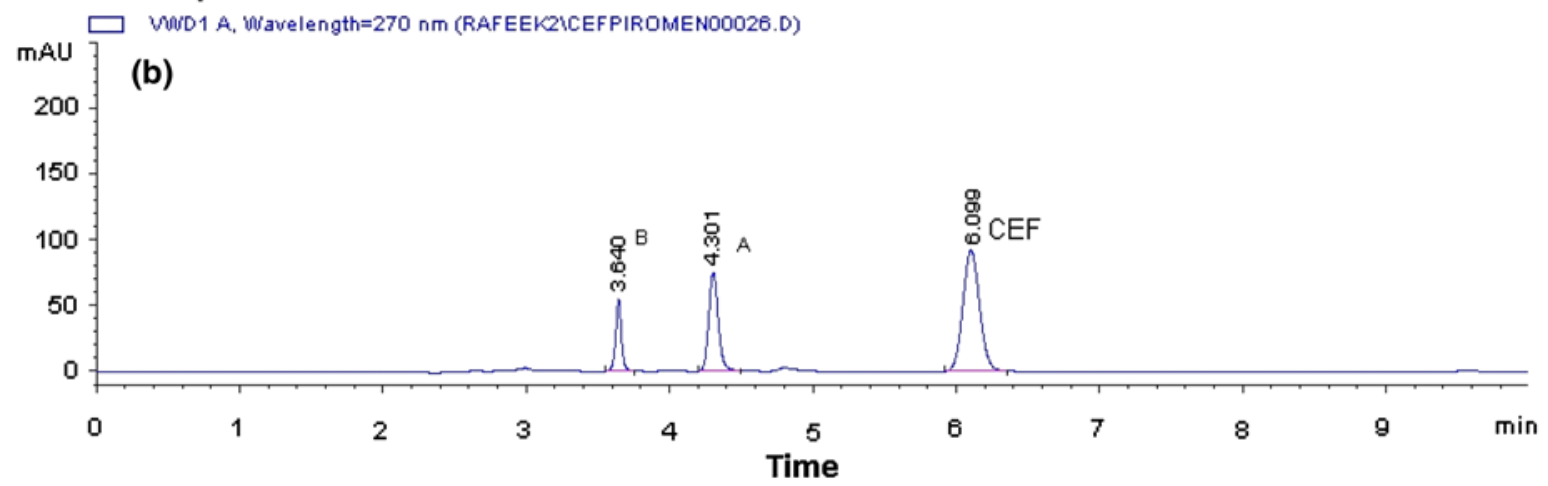

\section{Detector response}

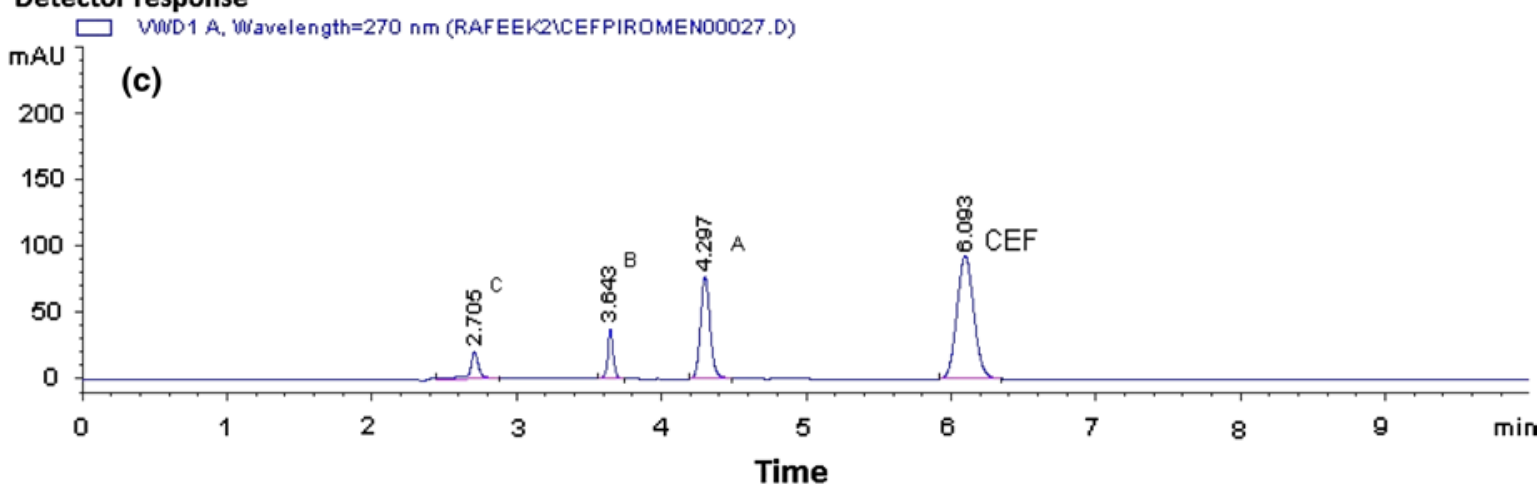

\section{Detector response}

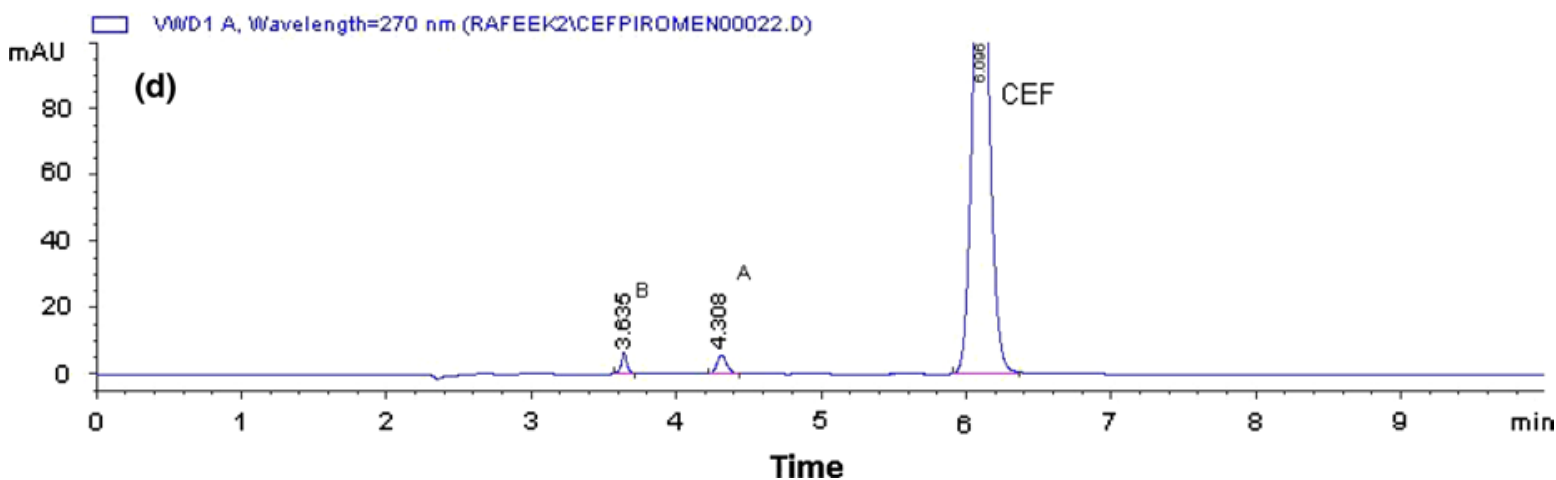

Fig. 1 HPLC chromatograms of: a Cefpirome sulfate $\left(30.0 \mu \mathrm{g} \mathrm{mL}^{-1}\right)$. b The laboratory mixture of cefpirome sulfate $\left(25.0 \mu \mathrm{g} \mathrm{mL}^{-1}\right)$ with its acid, alkaline or photo degradation products $\left(25.0 \mu \mathrm{g} \mathrm{mL}^{-1}\right)$ showing degradation products $A$ and $B$. c The laboratory mixture of cefpirome sulfate $\left(25.0 \mu \mathrm{g} \mathrm{mL}^{-1}\right)$ with its oxidative degradation products (25.0 $\left.\mu \mathrm{g} \mathrm{mL}^{-1}\right)$ showing degradation products $A, B$ and $C$. d The dosage form of cefpirome sulfate $\left(45.0 \mu \mathrm{g} \mathrm{mL}^{-1}\right)$ at the expiry date showing degradation products $A$ and $B$ 